\title{
BUSER TIKUS DENGAN MOUSETRAP
}

\author{
Bella Rizki Dwi Fitriana, Elsa Novemi Amelia, Laila Rahmah, Mahvira Fitra Aprilia. \\ bellafitriana43@gmail.com \\ Mahasiswa Fakultas Ilmu Kesehatan
}

\begin{abstract}
ABSTRAK
Tikus merupakan mamalia yang sangat merugikan dan menganggu kehidupan serta kesejahteraan manusia. Jika tikus dibiarkan maka populasinya akan bertambah. Tikus berada di lingkungan yang kotor, kumuh, dan lembab. Tikus juga merupakan salah satu vektor penyakit. Penyakit yang ditimbulkan oleh tikus salah satunya adalah Leptospirosis. Jenis pengabdian masyarakat ini adalah pengabdian masyarakat di 2 pesantren dengan membuat alat perangkap tikus atau moustrap. Moustrap diberikan kepada seluruh warga Pondok Pesantren Modern Gaza dan Pondok Pesantren Qur'an Al'Munnawir. Dalam pengabdian masyarakat ini pengabdi melakukan pendidikan mengenai tikus dan penyakit yang di sebarkan oleh tikus. Dan pelatihan berisi pembuatan alat perangkap tikus atau moustrap yang terbuat dari limbah botol bekas air mineral. Pengabdian ini menunjukkan bahwa penggunaan Mousetrap berpengaruh terhadap jumlah populasi tikus pada pondok pesantren modern Gaza dan Pondok Pesantren Al-Quran Al Munawwir. Kesimpulan dari pengabdian masyarakat ini adalah adanya perbedaan pengetahuan dan sikap pada saat pretest dan posttest sehingga mousetrap dapat mepengaruhi pengurangan resiko terjadinya penyakit yang disebabkan oleh vektor tikus. Untuk penelitian selanjutnya diharapkan dapat menggunakan metode dan media lain yang lebih menarik dalam pengabdian masyarakat di pondok pesantren..
\end{abstract}

Kata Kunci: Tikus, Mousetrap, Vektor.

\section{PENDAHULUAN}

\section{Latar Belakang}

Tikus pemukiman adalah tikus yang berada di lingkungan permukiman manusia, yang sudah beradaptasi dengan baik terhadap aktifitas dan kehidupan manusia (Priyambodo 2003). Jenis tikus yang sering ditemui pada daerah pemukiman adalah Rattus Rattus Diardii, R. No rvegichus, dan Musculus (Amstrom 2003). Sullivan (2002) menyatakan bahwa umumnya, tikus pemukiman berada didaerah kota dengan penduduk yang padat dan sanitasi yang kurang baik. Hubungan tikus dengan manusia sering kali bersifat parasitisme, (Pryambodo S, 2006) tikus dan mencit adalah hewan pengerat (Rodensia) yang lebih dikenal sebagai hama tanaman pertanian, perusak barang digudang dan hewan pengganggu dan menjijikan di perumahan.

Penyakit yang ditimbulkan tikus salah satunya Leptospirosis. Leptospirosis merupakan masalah kesehatan masyarakat diseluruh dunia, khususnya di negaranegara yang beriklim tropis dan subtropis, serta memiliki curah hujan yang tinggi (Rusmini,2011). Leptospirosis pada manusia ditularkan oleh hewan yang terinfeksi Leptospira dengan reservoir utama adalah tikus (Pramestuti N, Ikawati B, \& Astuti NT, 2012:12).

Pengendalian tikus penting dilakukan untuk mengurangi kepadatan tikus, pengendalian dapat dilakukan dengan memberikan intervensoi terhadap berbagai aspek yaitu sumber infeksi (Host, Reservoir, maupun carier), jalur penularan 
penyakit dan manusia (Rusmini,2010 : 110 ). Untuk melakukan pengendalian pada sumber infeksi salah satu penyakit yang diakibatkan tikus yaitu Leptospirosis dapat dilakukan dengan mengendalikan atau control terhadap populasi tikus. Salah satu metode pengendalian tikus yaitu dengan menggunakan perangkap. Perangkap yang digunakan berupa botol plastik dari bahan dasar yang diperoleh dari barang-barang yang tidak dipakai (limbah botol air mineral) hingga menjadi mousetrap. Jadi berdasarkan latar belakang diatas, peneliti tertarik membuat penelitian yang berjudul : Buser Tikus dengan Mousetrap.

\section{Kondisi dan potensi wilayah}

Kondisi wilayah Pondok Pesantren Gaza berada di tengah permukiman warga dan dekat dengan jalan raya. Pondok pesantren Gaza memiliki beberapa gedung asrama putra-putri, majelis, ruang kelas, kamar mandi, tempat menjemur baju. Adapula sumur tempat penampungan air yang letaknya di depan pintu masuk kamar mandi putri, tetapi atap sumur tersebut tidak tertutup dengan sempurna, hanya sebagian yang tertutup. Sehingga air yang terdapat di Pondok Pesantren Modern Gaza dapat tercemar.

Kondisi Wilayah Pondok Pesantren Qur'an Al'munnawir berada didekat permukiman warga . Dimana kondisi pada pesantren ini secara umum terlihat rapih dan bersih. Tetapi kamar mandi pada pesantren ini tidak dikelola dengan baik. Banyak piring dan peralatan makan lainnya berserakan, dan terdapat baju-baju yang dijemur disembarang tempat. Sehingga dikhawatirkan dapat menjadi sarang tikus.

\section{Lokasi}

Lokasi pembuatan perangkap tikus berada di Pondok Pesantren Modern Gaza Bogor dan Pondok Pesantren Qur'an AlMunawwir Bogor. Pondok pesantren Gaza terletak di Kp.Rawataman Tanah Sareal Bogor,Indonesia. Pondok pesantren Gaza memiliki beberapa gedung asrama putraputri, majelis, ruang kelas, kamar mandi, tempat menjemur pakaian.Pondok Pesantren Gaza memiliki sumur yang letaknya dekat kamar mandi putri, tetapi atap sumur tersebut tidak tertutup dengan sempurna, hanya sebagian yang tertutup. Pondok Pesantren Gaza pernah mengalami adanya bangkai tikus di dalam sumur. Sehingga air-air yang keluar dari sumur tersebut mengeluarkan bau tidak sedap dan terjadi pencemaran air. Selain itu juga terdapat tempat pembuangan sampah yang terbuka yang letaknya tepat di depan gerbang asrama putri. Sampah-sampah tersebut tidak di kelola dengan baik, sehingga sampah tersebut menumpuk dan menjadi tempat bersarangnya nyamuk, lalat dan tikus. Banyaknya tempat bersarang tikus menjadikan warga santriwati Pondok Pesantren Gaza khawatir, oleh sebab itu kami akan membantu warga Pondok Pesantren Gaza untuk mengurangi populasi tikus dengan mengolah limbah botol plastik sebagai alat perangkap tikus yang kami sebut dengan mousetrap.

Pondok Pesantren Qur'an AlMunawwir terletak di Kp. Sumur Wangi rt 03 rw 08 kelurahan kayu manis kecamatan Tanah Sareal kota Bogor, dimana pondok pesantren ini memiliki lingkungan yang bersih dan rapi. Di depan gerbang terdapat aliran pembuangan air yang bersih karena aliran tersebut dikelola dengan baik oleh warga sekitar pondok. Tetapi kamar mandi yang ada pada kamar santri tidak di kelola dengan baik, karena banyak pakaian dan piring yang berserakan dan di letakkan tidak beraturan, hal tersebut di khawatirkan dapat menjadi tempat bersarangnya tikus. Oleh sebab itu kami akan membantu Pondok Pesantren Qur'an Al-Munawwir untuk mencegah agar tempat-tempat tersebut tidak menjadi tempat bersarangnya tikus, dengan cara membuat alat perangkap tikus atau yang biasa kami sebut dengan Mouse Trap. 


\section{METODE PENELITIAN}

\section{Teknik Penelitian}

\section{Cara Pelaksanaan}

Cara pelaksanaan pada penelitian ini yaitu terdiri dari 2 cara, Pendidikan dan Pelatihan

a. Pendidikan

Pendidikan yang dilakukan pada penelitian ini berupa penyuluhan kepada warga Pondok Pesantren Modern Gaza dan Pondok Pesantren Qur'an Al'Munnawir Bogor. Materi penyuluhan yang diberikan yaitu mengenai bahaya lingkungan yang kotor, bahaya dari tikus, dan fungsi dari mousetrap.

b. Pelatihan

Pelatihan yang dilakukan pada penelitian ini berupa cara pembuatan mousetrap dari bahan dasar yang diperoleh dari barang-barang yang tidak dipakai (limbah botol air mineral) hingga menjadi mousetrap.

2. Teknik Pengumpulan

Teknik pengumpulan data yang digunakan dalam penelitian ini yaitu observasi dan kuesioner.

a. Observasi

Observasi yang dilakukan berupa pengamatan lingkungan fisik yang terdiri dari gedung asrama putra-putri, majelis, ruang kelas, kamar mandi, dan tempat menjemur pakaian di Pondok Pesantren Modern Gaza dan Pondok Pesantren Qur'an Al'Munnawir Bogor.

b. Kuesioner

Kuesioner diberikan kepada seluruh warga Pondok Pesantren Modern Gaza dan Pondok Pesantren Qur'an Al'Munnawir.

Dalam penelitian ini kuesioner berisi beberapa pertanyaan mengenai pengetahuan dan sikap yang bertujuan untuk mengetahui seberapa besar pengaruh pendidikan dan pelatihan yang telah diberikan oleh peneliti.

3. Teknik Pengolahan

Teknik pengolahan menggunakan SPSS dimana data yang diperoleh akan melalui beberapa tahapan yaitu input, coding, output

4. Analisis Data

Analisis data dilakukan setelah mendapatkan hasil dari pengolahan data,

5. Tahap Penyelesaiian masalah

a. Memberikan kuesioner (pre test) kepada warga Pondok Pesantren Modern Gaza dan Pondok Pesantren Qur'an Al'Munnawir

b. Melakukan edukasi kepada warga Pondok Pesantren Modern Gaza dan Pondok Pesantren Qur'an Al'Munnawir

c. Pemasangan mousetrap ditempattempat yang berpotensi bersarangnya tikus.

d. Pengamatan (Penempatan mousetrap, pengetahuan dan sikap warga Pondok Pesantren Modern Gaza dan Pondok Pesantren Qur'an Al'Munnawir)

e. Memberikan kuesioner (post test) kepada warga Pondok Pesantren Modern Gaza dan Pondok Pesantren Qur'an Al'Munnawir

\section{Pencapaian Tujuan Program}

a. Adanya peningkatan pengetahuan serta sikap warga Pondok Pesantren Modern Gaza dan Pondok Pesantren Qur'an Al'Munnawir terhadap bahaya lingkungan fisik yang kotor dan bahaya tikus.

b. Menurunkan angka populasi tikus yang berada di Pondok Pesantren 
Modern Gaza dan Pondok Pesantren Qur'an Al'Munnawir

c. Menurunkan angka kesakitan yang sebabkan oleh tikus pada warga
Pondok Pesantren Modern Gaza dan Pondok Pesantren Qur'an Al'Munnawir

\section{BIAYA DAN JADWAL KEGIATAN}

Berikut adalah rincian penganggaran kegiatan penelitian :

\begin{tabular}{|c|c|c|c|c|c|c|}
\hline No. & DESKRIPSI & QTY & & $\begin{array}{c}\text { HARGA/UNI } \\
\mathrm{T}\end{array}$ & ЛМI_AH & TOTAL \\
\hline 1 & \multicolumn{6}{|l|}{ Keseluretariatan } \\
\hline & $\begin{array}{l}\text { Penggandaan proposal \& } \\
\text { surat }\end{array}$ & 2 & Lembar & Rp200.000 & Rp 400.000 & \\
\hline & Stempel Kegiatan & 1 & Buah & Rp200.000 & $\operatorname{Rp} 200.000$ & \\
\hline & Kop Amplop & 2 & Buah & Rp18.500 & $\operatorname{Rp} 37.000$ & \\
\hline & Kertas A4 80 grm & 2 & Rim & Rp32.000 & Rp64.000 & \\
\hline & Ball point & 2 & Pack & R甲40.000 & Rp\$0.000 & \\
\hline & Map & 1 & Pack & Rpl 16.000 & Rpl6.000 & \\
\hline & Lem stick & 2 & Buah & $\mathrm{Rp} 3.000$ & Rp5 5000 & \\
\hline & Tali kur & 4 & buah & $\operatorname{Rp} 5.000$ & $\operatorname{Rp} 20.000$ & \\
\hline & Sepidol & 4 & buah & $R p 7.000$ & $\operatorname{Rp28.000}$ & \\
\hline & Gunting & 4 & buah & $\operatorname{Rp} 20.000$ & $\operatorname{Rp} 80.000$ & \\
\hline & Curter & 4 & buah & Rpl5.000 & Rp60.000 & \\
\hline & Obeng & 5 & buah & $\operatorname{Rp} 20.000$ & Rpl00.000 & \\
\hline & isi staples & 2 & buah & $\mathrm{Rp} 5.000$ & Rpl0.000 & \\
\hline & Staples & 2 & buah & $\mathrm{Rp} 8.000$ & Rpl6.000 & \\
\hline & Isolasi & 1 & roll & Rp2.500 & $R p 2.500$ & \\
\hline & Double tipe & 2 & roll & Rp 6.000 & Rp12.000 & \\
\hline & Plastik Laminating & 20 & buah & $R p 2.000$ & $\operatorname{Rp} 40.000$ & \\
\hline & Klip & 10 & Lembar & $\mathrm{Rp} 2.000$ & $\operatorname{Rp} 20.000$ & \\
\hline & Sumpit & 2 & Pack & $\operatorname{Rp} 15.000$ & $\operatorname{Rp} 30.000$ & \\
\hline & Karet gelang & 2 & Pack & Rp̣10.000 & $\operatorname{Rp20.000}$ & \\
\hline & Benang & 2 & Ball & Rp15.000 & $\operatorname{Rp30.000}$ & \\
\hline & Tikus & 6 & ekor & $\mathbb{R}$ 10.000 & Rp 60.000 & \\
\hline & Handscoon(sarung tangan) & 2 & dus & R甲50.000 & Rpl00.000 & \\
\hline & Masker & 4 & dus & $\operatorname{Rp} 30.000$ & Rpl20.000 & \\
\hline & Tissu & 2 & buah & Rp̣15.000 & Rp30.000 & \\
\hline & Benang Layangan & 2 & roll & Rp5.000 & Rpp10.000 & \\
\hline & Handsoap & 4 & buah & $\operatorname{Rp3} 30.000$ & Rpl20.000 & \\
\hline & Materai & 3 & buah & $\mathrm{Rp} 8.000$ & $\operatorname{Rp} 24.000$ & \\
\hline & Amplop tali & 2 & buah & $R p 2.000$ & $R_{p} 4.000$ & \\
\hline Sub to & al Kesekretariatan & & & & & $\begin{array}{c}\mathrm{Rp} 1.739 .50 \\
0\end{array}$ \\
\hline
\end{tabular}




\begin{tabular}{|c|c|c|c|c|c|c|}
\hline 2 & Pub.Dek.Dok_Log & & & & & \\
\hline & Sewa sound system lengkap & 4 & hari & Rp200.000 & Rp800.000 & \\
\hline & Sewa infocus & 4 & hari & Rq400.000 & $\begin{array}{c}\text { Rpl } .600 .0 \\
00\end{array}$ & \\
\hline & Poster & 4 & buah & Rpl0.000 & Rp 40.000 & \\
\hline & Spanduk & 2 & buah & Rp200.000 & Rp400.000 & \\
\hline & Banner & 2 & buah & $\operatorname{Rp} 75.000$ & Rpl50.000 & \\
\hline & Sewa 2 kamera dslr lengkap & 4 & hari & Rp500.000 & $\begin{array}{c}\text { Rp2,000,0 } \\
00\end{array}$ & \\
\hline & Plakat & 2 & buah & Rp300.000 & Rp 600.000 & \\
\hline & Kaos & 4 & buah & Rpl00.000 & Rp400.000 & \\
\hline & Hadiah & 6 & Buah & Rp200.000 & $\begin{array}{c}\text { Rpl } 1.200 .0 \\
00\end{array}$ & \\
\hline \multicolumn{6}{|c|}{ Sub total Pub.Dek. Dok.Log } & $\begin{array}{r}\text { Rp5.190.00 } \\
0 \\
\end{array}$ \\
\hline 3 & \multicolumn{6}{|l|}{ Kousumsi } \\
\hline & Snack & 400 & dus & Rp 6.000 & $\begin{array}{c}\mathrm{Rp} 2.400 .0 \\
00\end{array}$ & \\
\hline & Nasi Kotak & 150 & kotak & Rpl0.000 & $\begin{array}{c}\text { Rpl } 1.500 .0 \\
00\end{array}$ & \\
\hline & Kue(Talas bogor) & 14 & kotak & Rp35.000 & Rp 490.000 & \\
\hline \multicolumn{6}{|c|}{ Sub total Konsumsi } & $\begin{array}{r}\text { RP4.390.00 } \\
0 \\
\end{array}$ \\
\hline 4 & \multicolumn{6}{|l|}{ Humas } \\
\hline & Transportasi & 4 & $\begin{array}{c}\text { pertemua } \\
\text { n }\end{array}$ & Rp200.000 & Rp 800.000 & \\
\hline & Pulsa & 2 & orang & Rpl00.000 & $\mathrm{Rp} 200.000$ & \\
\hline \multicolumn{6}{|c|}{ Sub total Humas } & $\begin{array}{r}\text { Rpl.000.00 } \\
0\end{array}$ \\
\hline \multicolumn{6}{|c|}{ Total Pengeluaran } & $\begin{array}{r}\text { Rpl2.319.5 } \\
00 \\
\end{array}$ \\
\hline
\end{tabular}

Berikut merupakan jadwal kegiatan:

\section{Program Penelitian}

$$
\begin{array}{r}
\text { Pengamatan } \\
\text { Praktik }
\end{array}
$$

Lingsih (Lingkungan bersih)

$$
\text { Penyuluhan }
$$

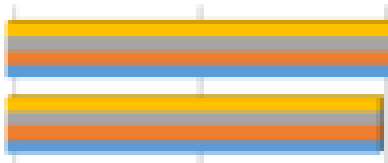




\section{KESIMPULAN}

\section{Tujuan}

1 Tujuan Umum

Untuk mengetahui pengaruh mousetrap terhadap populasi tikus di Pondok Pesantren Modern Gaza dan Pondok Pesantren Qur'an Al Munnawir Bogor.

2 Tujuan Khusus

2.1 Untuk mengetahui tingkat efektifitas mousetrap terhadap populasi tikus.

2.2 Untuk mengetahui pengaruh populasi tikus terhadap kesehatan warga Pondok Pesantren Modern Gaza dan Pondok Pesantren Qur'an Al Munnawir Bogor.

2.3 Untuk mencegah terjadinya peningkatan populasi tikus di sekitar Pondok Pesantren Modern Gaza dan Pondok Pesantren Qur'an Al Munnawir Bogor.

\section{Luaran}

1 Dengan selesainya penelitian ini diharapkan masyarakat di pondok pesantren dapat memahami dan mengaplikasikan MouseTrap (Perangkap Tikus) dalam kehidupan sehari-hari.

2 Dari program ini diharapkan masyarakat dapat mengetahui dampak dari hewan mamalia tikus.

3 Melalui program ini diharapkan masyarakat pondok pesantren dapat mengetahui penyakit salah satunya penyakit Leptospirosis yang diakibatkan oleh tikus. Serta dapat menerapkan pola hidup sehat agar tidak terjadi peningkatan populasi tikus.

\section{Manfaat Penelitian}

1 Manfaat Primer : Mendapatkan lingkungan yang bersih karena MouseTrap terbuat dari limbah botol plastik dan dapat mengurangi populasi tikus didaerah pondok pesantren.

2 Manfaat Sekunder : Memiliki Pondok Pesantren yang bersih, terhindar dari tikus, yang dimana tikus daoat menyebabkan berbagai macam penyakit. 


\section{REFERENSI}

Umini Irawati et.all. 2014. Efektivitas Pemasangan Berbagai Model Perangkap Tikus Terhadap Keberhasilan Penangkapan Tikus Di Kelurahan Bangetayu Kulon Kecamatan Genuk Kota Semarang Tahun 2014. Semarang: Unnes Journal of Public Health.

Sonia Suci Ramadhani. 2016. Uji Rodentisida, Perangkap, dan Repelen, Serta Persepsi Mayarakat Terhadap Tikus Permukiman di Cibinong, Bogor. Skripsi. Departeman Proteksi Tanaman Fakultas Pertaninan Bogor.
B. Yuliadi dkk. 2016. Tikus Jawa Teknik Survei di Bidang Kesehatan. Jakarta: Lembaga Penerbit Badan Penelitian dan Pengembangan.

Https://g.co/kgs/zsKKwe Pondok Pesantren Qur'an Al-Munawwir Bogor (Di Akses pada 25 November 2017. 13.16)

Https:/g.co/kgs/YYhXss $\quad$ Pondok Pesantren Gazha Al Islami.. (Di Akses pada 25 November 2017. 13.16) 